\title{
Adjuvant External Beam Radiotherapy \pm Brachytherapy in Endometrial Cancer: A Retrospective Study from Faculty of Medicine, Chiang Mai University
}

\author{
Ekkasit Tharavichitkul1 ${ }^{*}$, Sukon Prasitwattanaseree ${ }^{2}$, Patrinee Traisathit ${ }^{2}$, \\ Cholthicha Thipmate2, Somvilai Chakrabandhu1, Pitchayaponne Klunklin1, \\ Wimrak Onchan1, Razvan M. Galalae ${ }^{3}$, Imjai Chitapanarux ${ }^{1}$ \\ ${ }^{1}$ The Division of Therapeutic Radiology and Oncology, Faculty of Medicine, Chiang Mai University, Chiang Mai, \\ Thailand \\ ${ }^{2}$ Biostatistics and Applied Statistics Laboratory, Department of Statistics, Faculty of Science, Chiang Mai \\ University, Chiang Mai, Thailand \\ ${ }^{3}$ Faculty of Medicine, Christian-Albretch University, Kiel, Germany \\ Email: paan 31@hotmail.com
}

Received 3 January 2015; accepted 23 January 2015; published 29 January 2015

Copyright (C) 2015 by authors and Scientific Research Publishing Inc.

This work is licensed under the Creative Commons Attribution International License (CC BY).

http://creativecommons.org/licenses/by/4.0/

(c) (i) Open Access

\begin{abstract}
Purpose: To report the retrospective study of external beam radiotherapy (EBRT) \pm intravaginal brachytherapy (IVBT) as adjuvant treatment for endometrial cancer. Materials and Methods: From 2001-2009, 152 patients received complete surgical staging for endometrial carcinoma and were designed by a multidisciplinary team to receive EBRT \pm IVBT. The treatment results and late toxicities were evaluated and recorded. Results: At the median follow-up time of $\mathbf{4 3}$ months, the disease-free survival, metastasis-free survival and overall survival rates were $96.9 \%, 96.9 \%$ and $96.9 \%$, respectively. Stage and age showed the statistical significance with the p-value of less than 0.001. From five to ten percent of patients developed Grades 1-2 late gastrointestinal and genitourinary toxicities, respectively. Conclusion: The using of adjuvant EBRT \pm IVBT for endometrial carcinoma yielded treatment results and acceptable toxicities.
\end{abstract}

\section{Keywords}

Endometrial Cancer, Adjuvant Treatment, External Beam Radiotherapy

\footnotetext{
${ }^{*}$ Corresponding author.
}

How to cite this paper: Tharavichitkul, E., et al. (2015) Adjuvant External Beam Radiotherapy \pm Brachytherapy in Endometrial Cancer: A Retrospective Study from Faculty of Medicine, Chiang Mai University. Journal of Cancer Therapy, 6, 115-121. http://dx.doi.org/10.4236/jct.2015.62012 


\section{Introduction}

Endometrial cancer was one of gynecologic cancers in Thailand. From the study of Tangjitgamol et al., the most common symptom was abnormal uterine bleeding (87.3\%) and 78\% of them had early stage disease [1]. Radical surgery \pm pelvic lymph node dissection (PLND) is the primary treatment for endometrial cancer. Intermediaterisk and high-risk groups had a higher recurrence rate than the low-risk group. For further treatment in these groups, four randomized studies demonstrated a reduction of pelvic recurrences with addition adjuvant external beam radiotherapy (EBRT) plus or minus intravaginal brachytherapy (IVBT) as adjuvant treatment. The most benefit of radiotherapy is to reduce recurrences at the vaginal cuff which is the most common site of failure. In the intervention arm, the recurrence rates were between $1.9 \%-4 \%$. According to these studies, EBRT \pm IVBT has been used to treat as adjuvant treatment for intermediate-risk to high-risk endometrial cancer [2]-[5]. In our department, adjuvant radiotherapy for endometrial cancer has been used for more than 10 years. It is interesting to investigate the treatment results of adjuvant radiotherapy in endometrial cancer in our institute. This study had planned to evaluate results of adjuvant EBRT \pm IVBT for endometrial carcinoma in Faculty of Medicine, Chiang Mai University.

\section{Materials and Methods}

After the acceptance of institution board review, patients who had $\geq 18$ year old, pathologically proven endometrioid adenocarcinoma with intermediate to high risk for recurrences, Stages I-III according to the International Federation of Gynecology and Obstetrics (FIGO) staging edition of 1998. Complete surgical staging (total abdominal hysterectomy \& bilateral salpingo-oophorectomy: TAH \& BSO) plus pelvic lymph node dissection (PLND) was performed and the pathological results were reviewed and designed to receive adjuvant EBRT according to the consensus of multidisciplinary team composed of gynecologic oncologist and radiation oncologist. From the year of 2001 to 2009, there were 199 patients with endometrial cancer who were treated and 152 patients were designed to treat by EBRT \pm IVBT. All patients received "standard" EBRT to whole pelvis. Vaginal stump and pelvic lymph node were identified as Clinical Target Volume (CTV). For the EBRT, 6 or 10 MV photon was used to treat the vaginal stump and pelvic lymph nodes (obturator, internal iliac, external iliac, and common iliac lymphnodes) in 2- or 4-field techniques. According to the anatomy of the vaginal cuff, either intravaginal cylinder or vaginal ovoid were applied to the areas of vaginal stump and upper third of vaginal length with the prescribed dose at $5 \mathrm{~mm}$ from applicator surface. All patients received IVBT with the dose of 5.5 - $7 \mathrm{~Gy}$ in 1 - 4 fractions.

After the treatment finished, patients were scheduled to visit for per vaginal examination (PV exam) in the follow-up program. The follow-up program schedule is every 3 months in the first 3 years after treatment, 6 monthly in years 4 and 5 , then annually after five years. A vaginal examination was performed to evaluate the disease status according to World Health Organization (WHO) criteria [6]. Investigations (tissue biopsy, medical imaging or laboratories) for disease progression were performed as indicated when patients presented with suggested symptoms. Late toxicities were evaluated according to the Radiation Therapy Oncology Group/European Organization of Research and Treatment of Cancer (RTOG/EORTC) late toxicity criteria [7].

All descriptive and qualitative analyses were evaluated. Survival analysis data were calculated by KaplanMeier method and log-rank test and univariate analysis were used to measure the relationship between patient factors to the treatment results using Cox's proportional hazards model [8]-[10].

\section{Results}

From 2002-2009, 152 patients with endometrial adenocarcinoma who received complete surgical staging and adjuvant external beam radiation therapy were enrolled. Thirty percent (46 patients) were Staged IIIC according to FIGO1998 staging and thirty-eight percents (59 patients) were moderately differentiated histology. For the WPRT, 88\% of them (134 patients) received the dose of 50 Gy in 25 fractions. For intravaginal brachytherapy, $35 \%$ (53 patients) had no brachytherapy boost and the 57 patients (37.5\%) received the schedule of $2 \times 6$ Gy. The characteristic data were shown in Table 1, Figure 1 and Figure 2.

At the median follow-up time of 43 months (IQR = 55.5 months), the 5-yr disease-free survival, metastasisfree survival and overall survival rates were $96.9 \%$, 96.9\% and 96.9\%, respectively. All survival data were shown in Table 2. 


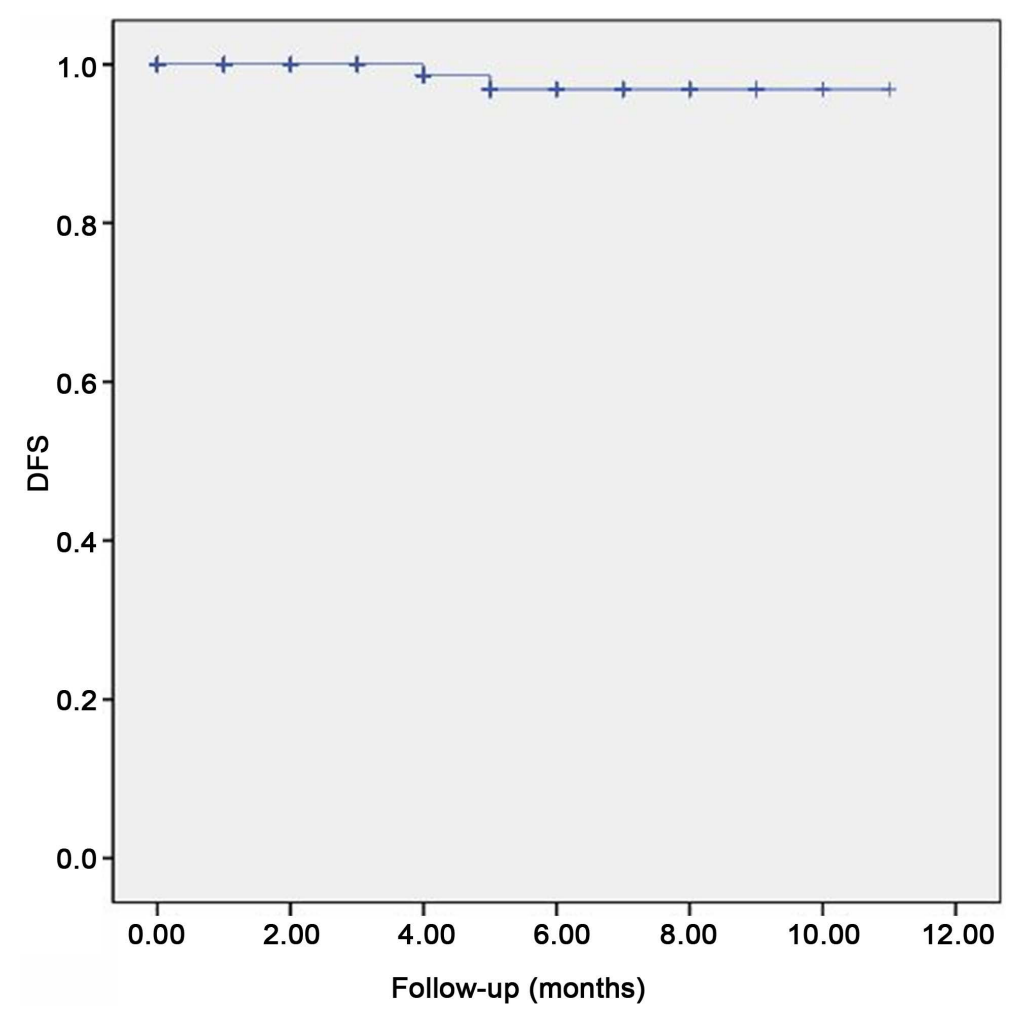

Figure 1. Kaplan-Meier curve showed disease-free survival rate.

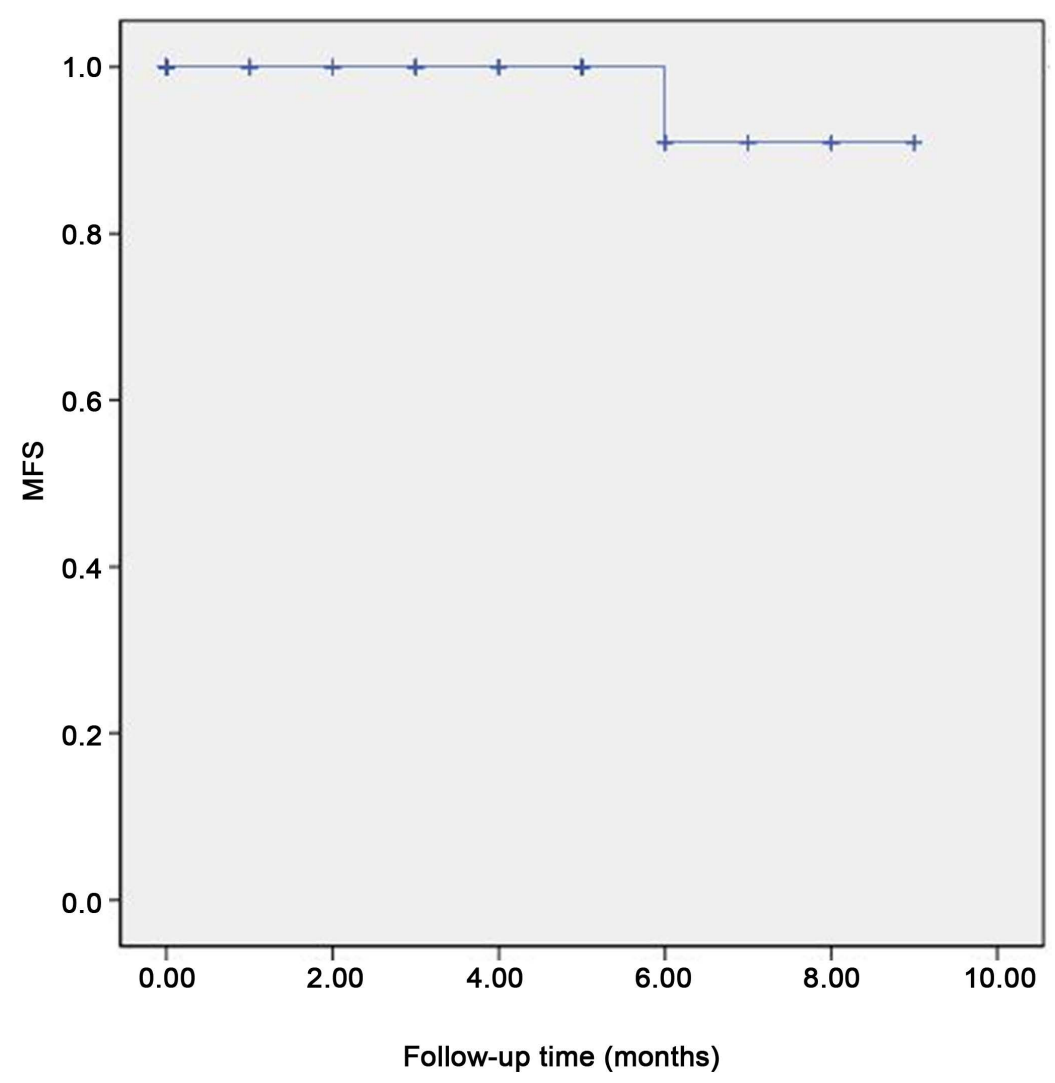

Figure 2. Kaplan-Meier curve showed metastasis-free survival rate. 
Table 1. Characteristics data.

\begin{tabular}{|c|c|}
\hline Parameters & Numbers (total $=152$ ) \\
\hline Age (years) & $\begin{array}{l}\text { Mean (SD) } 55.64 \text { (9.81) } \\
\text { Median (IQR) } 55 \text { (13.00) }\end{array}$ \\
\hline $\begin{array}{l}\text { Histology } \\
\text { Endometrioid adenocarcinoma }\end{array}$ & 152 \\
\hline $\begin{array}{c}\text { Pathological stage } \\
\text { IA } \\
\text { IB } \\
\text { IC } \\
\text { IIA } \\
\text { IIB } \\
\text { IIIA } \\
\text { IIIB } \\
\text { IIIC }\end{array}$ & $\begin{array}{c}1(0.7 \%) \\
9(5.9 \%) \\
33(21.7 \%) \\
9(5.9 \%) \\
25(16.4 \%) \\
27(17.8 \%) \\
2(1.3 \%) \\
46(30.3 \%)\end{array}$ \\
\hline $\begin{array}{c}\text { Grade } \\
\text { Well-differentiated } \\
\text { Moderately differentiated } \\
\text { Poorly differentiated } \\
\text { Others }\end{array}$ & $\begin{array}{c}46(30.3 \%) \\
59(38.8 \%) \\
37(24.3 \%) \\
10(6.6 \%)\end{array}$ \\
\hline $\begin{array}{c}\text { WPRT } \\
50 \text { Gy/25 Fractions } \\
\text { Others }\end{array}$ & $\begin{array}{c}134(88.2 \%) \\
18(11.8 \%)\end{array}$ \\
\hline $\begin{array}{l}\text { Brachytherapy } \\
\text { No boost } \\
2 \times 6 \mathrm{~Gy} \\
4 \times 6 \mathrm{~Gy} \\
1 \times 7 \mathrm{~Gy} \\
\text { Others }\end{array}$ & $\begin{array}{c}53(34.9 \%) \\
57(37.5 \%) \\
11(7.2 \%) \\
17(11.2 \%) \\
14(9.2 \%)\end{array}$ \\
\hline Total treatment time (days) & $\begin{array}{l}\text { Mean (SD) } 45.59 \text { (12.78) } \\
\text { Median (IQR) } 42(12.00)\end{array}$ \\
\hline
\end{tabular}

Table 2. Treatment results in patient groups.

\begin{tabular}{cccc}
\hline Results & Disease-free rate (\%) & Metastasis-free survival rate (\%) & Overall survival rate (\%) \\
\hline Stages Ia, Ib, Ic & $95 \%$ at 4 years & $95 \%$ at 4 years & $95 \%$ at 4 years \\
Stages IIIa, IIIb, IIIc & $96.4 \%$ at 5 years & $95 \%$ at 4 years & $95 \%$ at 4 years \\
All groups & $96.9 \%$ at 5 years & $96.9 \%$ at 5 years & $96.9 \%$ at 5 years \\
\hline
\end{tabular}

For risk factor analyses, stage and age showed statistical significance with the p-value of $<0.001$ in both factors. No statistical significance was observed in myometrial invasion, cervical involvement and grade. All parameters were shown in Table 3.

For toxicity profiles, the incidences of late gastrointestinal, genitourinary, skin and subcutaneous tissue toxicities (all grades) were 10.5\%, 5.3\%, 13.8\% and 11.2\%, respectively. No Grades 3-4 toxicity was found (Table 4).

\section{Discussions}

Radiation therapy has been used for a long time as adjuvant treatment for endometrial cancer. Before the publications of randomized studies for adjuvant radiotherapy, many studies showed the promising results with 5-year overall survival rate more than $80 \%$ without severe toxicity [11] [12].

The Gynecologic Oncology Group (GOG) performed a similar trial in patients with lymph node staging (GOG 99). That trial had a slightly different definition of intermediate risk, and included Stage IB, Stage IC, and occult Stage II (involvement of the cervix) disease of all grades. This study showed the improvement in pelvic and vaginal recurrences; the 4-year loco-regional relapse rates were $9 \%$ and $1.5 \%$ in irradiated versus non-irra- 
Table 3. Risk factor analyses.

\begin{tabular}{|c|c|c|c|c|c|c|}
\hline Variables & HR & $95 \%$ CI & $\mathrm{p}$-value & Adjusted HR & $95 \%$ CI & p-value \\
\hline Stage & & & 0.001 & & & $<0.001$ \\
\hline Ia, Ib, Ic & 1.000 & - & & 1.000 & & \\
\hline IIa, IIb & 1.292 & $0.484-3.454$ & 0.609 & 1.362 & $0.508-3.647$ & 0.539 \\
\hline IIIa & 3.369 & $1.582-7.176$ & 0.002 & 4.280 & $1.958-9.227$ & $<0.001$ \\
\hline \multicolumn{7}{|c|}{ Myometrial invasion } \\
\hline Yes & 0.611 & $0.334-1.118$ & 0.110 & & & \\
\hline No & 1.000 & - & & & & \\
\hline Grade & & & 0.733 & & & \\
\hline Well-differentiated & 0.898 & $0.261-3.085$ & 0.864 & & & \\
\hline Moderately differentiated & 0.969 & $0.290-3.233$ & 0.959 & & & \\
\hline Poorly differentiated & 1.306 & $0.379-4.495$ & 0.672 & & & \\
\hline Others & 1.000 & - & & & & \\
\hline \multicolumn{2}{|c|}{ Cervix involvement } & & 0.186 & & & \\
\hline Endocervical gland & 1.151 & $0.656-2.020$ & 0.623 & & & \\
\hline Stromal & 2.149 & $0.941-4.908$ & 0.070 & & & \\
\hline None & 1.000 & - & & & & \\
\hline \multicolumn{7}{|l|}{ Age } \\
\hline Less than 60 & 1.000 & - & & 1.000 & & \\
\hline More than 60 & 3.703 & $2.206-6.215$ & $<0.001$ & 4.675 & $2.712-8.056$ & $<0.001$ \\
\hline
\end{tabular}

Table 4. Treatment toxicities.

\begin{tabular}{cc}
\hline Parameters & Numbers/Total (\%) \\
\hline Late Grades 1-2 GI Toxicity & $16 / 152(10.5 \%)$ \\
Late Grades 1-2 GU Toxicity & $8 / 152(5.3 \%)$ \\
Late Grades 1-2 Skin Toxicity & $21 / 152(13.8 \%)$ \\
Late Grades 1-2 Subcutaneous Tissue & $17 / 152(11.2 \%)$ \\
\hline
\end{tabular}

diated patients. The 4-year survival rate of $92 \%$ in the radiotherapy arm versus $86 \%$ with observation $(p=0.557)$ [2].

The Postoperative Radiation Therapy in Endometrial Carcinoma (PORTEC) randomized 715 patients with Grades 2 and 3 diseases and $<50 \%$ myometrial invasion (Stage IB) as well as patients with $\geq 50 \%$ invasion (Stage IC) and Grades 1-2 disease to receive either pelvic radiotherapy or no further treatment. This study showed the improvement in pelvic and vaginal recurrences; the 8-year loco-regional relapse rates were $15 \%$ and $4 \%$ in treating versus non-treated patients. The 8 -year overall survival rate were $71 \%$ with radiotherapy versus $77 \%$ with observation ( $p=0.18$ ). In toxicity profiles, there were $17 \%$ for $\mathrm{G} 1-2$ gastrointestinal and $8 \%$ for $\mathrm{G} 1-2$ genitourinary toxicities. Grades 3-4 toxicity was found in 3\% [3].

The study of MRC/ASTEC-EN5 published the results of postoperative radiotherapy in early stage endometrial cancer. Nine hundred and five women with intermediate-risk or high-risk early-stage disease from 112 centers were randomly assigned after surgery to observation (453 patients) or to external beam radiotherapy (452 patients). A target dose of 40 - 46 Gy in 20 - 25 daily fractions to the pelvis, treating five times a week, was speci- 
fied. After a median follow-up of 58 months, 135 women died. There was no evidence that overall survival with external beam radiotherapy was better than observation, hazard ratio $1.05(95 \%$ CI $0.75-1.48$; $p=0.77)$. 5-year overall survival was $84 \%$ in both groups. Although there was no benefit in terms of overall survival (hazard ratio 1.04; 95\% CI 0.84 - 1.29), brachytherapy was used in 51\% of observation group [4].

According to Aalders et al., a subgroup analysis in patients with deep myometrial invasion revealed that the rate of pelvic relapse was lower in the radiotherapy-treated patients, at $6.6 \%$ versus $14.7 \%$. In patients with both Grade 3 disease and deep invasion, a 10\% improvement in the cancer death rate was seen with the addition of pelvic radiotherapy, and the pelvic relapse rate was lower, at $4.5 \%$ versus $20 \%$ [5].

Our study showed good treatment results and acceptable toxicities. At the median follow-up time of 43 months, the 5-yr disease-free survival, metastasis-free survival and overall survival rates were $96.9 \%, 96.9 \%$ and $96.9 \%$, respectively. When compared to other studies $(1.9 \%-4 \%$ of the local recurrence rate), our results showed the same tendency. For toxicity profiles, the incidences of Late Grades 1-2 Gastrointestinal, Genitourinary, skin and subcutaneous tissue toxicities (all grades) were 10.5\%, 5.3\%, 13.8\% and 11.2\%, respectively. No patient developed serious toxicity (Grades 3-4) in our study. Uni-variate analysis showed the correlations in age and stage. These data represented the treatment results of EBRT \pm IVBT as adjuvant treatment of endometrial cancer in Northern Thailand.

In recent, the using of EBRT in early-stage endometrial cancer was changed. The phase 3 PORTEC-2 trial was devised to answer the question of whether IVBT is sufficient treatment to prevent vaginal recurrence. Patients who had the high intermediate-risk group with the following features were included in the study; age greater than 60 and Stage IC Grade 1 or 2, or Stage IB Grade 3, Stage IIA (except Grade 3 extending into the outer half of the myometrium). Over 400 patients were randomized to either external beam radiotherapy or vaginal cuff brachytherapy. There was no significant difference in the rates of vaginal and pelvic recurrence at three years which were $2 \%$ and $3.5 \%$ in the brachytherapy arm versus $1 \%$ and $0.6 \%$ in the external beam arm. Distant relapse rates were $5.7 \%$ with external beam versus $6.3 \%$ with brachytherapy. Toxicity and quality of life were evaluated and showed better outcomes in gastrointestinal toxicity (13\% in IVBT alone versus 54\% in EBRT arm) with IVBT as monotherapy [13]. With PORTEC 2 results, the use of IVBT as monotherapy is an attractive option in early-stage endometrial cancer.

Our study had interesting points to concern. Firstly, there were multiple schedules of IVBT in our patients at that time that might effect to treatment results and toxicities. After the year of 2009, we decided to revise our schedule to be simple. The IVBT was prescribed to $7 \mathrm{~Gy}$ in one fraction (at $5 \mathrm{~mm}$ from applicator surface) additional to EBRT $50 \mathrm{~Gy} / 25$ fractions to increase the dose at the mucosa of vaginal stump. The results of the new schedule will be further reported. Secondly, although no Grades 3-4 toxicity in our patients was observed, the incidences of Grades 1-2 gastrointestinal and dermatologic toxicities were more than ten percents. According to our previous publication of IVBT as monotherapy, only $4.3 \%$ of patients developed Grades 1-2 gastrointestinal toxicity [14]. This supports the using of IVBT as monotherapy to replace EBRT in selected patients, especially Stage I endometrial cancer. Thirdly, according to the results of PORTEC2 study, the role of EBRT \pm IVBT in our institute changed to the "high-risk" early stage, advanced stage or aggressive histology and the role of IVBT as monotherapy was also changed to the "intermediate-risk" early stage. So the adjuvant radiotherapy in endometrial cancer in our institute was obviously defined in accordance with pathological staging. The treat- ment results of adjuvant radiotherapy in the new era will be evaluated in the near future.

\section{Conclusion}

Our study showed the results of adjuvant radiation therapy for endometrial cancer in Faculty of Medicine, Chiang Mai University with good treatment results and no Grades 3-4 chronic toxicity was observed.

\section{Funding}

This study was supported by Faculty of Medicine, Chiang Mai University.

\section{Acknowledgements}

The author wishes to thank Faculty of Medicine, Chiang Mai University and all staffs in the division to support his study. 


\section{References}

[1] Tangjitgamol, S., Manusirivithaya, S., Srijaipracharoen, S., Khunnarong, J., Tanvanich, S., Katanyu, K., et al. (2010) Endometrial Cancer in Thai Women: Clinico-Pathological Presentation and Survival. Asian Pacific Journal of Cancer Prevention, 11, 1267-1272.

[2] Keys, H.M., Roberts, J.A., Brunetto, V.L., Zaino, R.J., Spirtos, N.M., Bloss, J.D., et al. (2004) A Phase III Trial of Surgery with or without Adjunctive External Pelvic Radiation Therapy in Intermediate Risk Endometrial Adenocarcinoma: a Gynecologic Oncology Group Study. Gynecologic Oncology, 92, 744-751. http://dx.doi.org/10.1016/j.ygyno.2003.11.048

[3] Creutzberg, C.L., van Putten, W.L., Koper, P.C., Lybeert, M.L., Jobsen, J.J., Wárlám-Rodenhuis, C.C., et al. (2000) Surgery and Postoperative Radio-Therapy versus Surgery Alone for Patients with Stage-1 Endometrial Carcinoma; Multicenter Randomized Trial. Lancet, 355, 1404-1411. http://dx.doi.org/10.1016/S0140-6736(00)02139-5

[4] ASTEC/EN.5 Study Group, Blake, P., Swart, A.M., Orton, J., Kitchener, H., Whelan, T., Lukka, H., et al. (2009) Adjuvant External Beam Radiotherapy in the Treatment of Endometrial Cancer (MRC ASTEC and NCIC-CTG EN.5 Randomised Trials): Pooled Trial Results, Systematic Review, and Meta-Analysis. Lancet, 373, 137-146. http://dx.doi.org/10.1016/S0140-6736(08)61767-5

[5] Aalders, J., Abeler, V., Kolstad, P. and Onsrud, M. (1980) Postoperative External Irradiation and Prognostic Parameters in Stage I Endometrial Carcinoma: Clinical and Histopathologic Study of 540 Patients. Obstetrics \& Gynecology, 56, 419-427.

[6] Miller, A.B., Hoogstraten, B., Staquet, M. and Winkler, A. (1981) Reporting Results of Cancer Treatment. Cancer, 47, 207-214. http://dx.doi.org/10.1002/1097-0142(19810101)47:1<207::AID-CNCR2820470134>3.0.CO;2-6

[7] Cox, J.D., Stetz, J. and Pajak, T.F. (1995) Toxicity Criteria of the Radiation Therapy Oncology Group (RTOG) and the European Organization for Research and Treatment of Cancer (EORTC). International Journal of Radiation Oncology Biology Physics, 31, 1341-1346. http://dx.doi.org/10.1016/0360-3016(95)00060-C

[8] Kaplan, E.L. and Meier, P. (1958) Non-Parametric Estimation from Incomplete Observations. Journal of the American Statistical Association, 53, 457-481. http://dx.doi.org/10.1080/01621459.1958.10501452

[9] Mantel, N. (1966) Evaluation of Survival Data and Two New Rank Order Statistics Arising in Its Consideration. Cancer Chemotherapy Reports, 50, 163-170.

[10] Cox, D.R. (1972) Regression Models and Life Tables. Journal of the Royal Statistical Society: Series B, 34, $187-220$.

[11] Nori, D., Merimsky, O., Batata, M. and Caputo, T. (1994) Postoperative High Dose-Rate Intravaginal Brachytherapy Combined with External Irradiation for Early Stage Endometrial Cancer: A Long Term Follow-Up. International Journal of Radiation Oncology*Biology*Physics, 30, 831-837. http://dx.doi.org/10.1016/0360-3016(94)90357-3

[12] Algan, O., Tabesh, T., Hanlon, A., Hogan, W.M., Boente, M. and Lanciano, R.M. (1996) Improved Outcome in Patients Treated with Postoperative Radiation Therapy for Pathologic Stage I/II Endometrial Cancer. International Journal of Radiation Oncology*Biology*Physics, 35, 925-933. http://dx.doi.org/10.1016/0360-3016(96)00188-5

[13] Nout, R.A., Smit, V.T., Putter, H., Jürgenliemk-Schulz, I.M., Jobsen, J.J., Lutgens, L.C., et al. (2010) Vaginal Brachytherapy versus Pelvic External Beam Radiotherapy for Patients with Endometrial Cancer of High-Intermediate Risk (PORTEC-2): An Open-Label, Non-Inferiority, Randomised Trial. Lancet, 375, 816-823. http://dx.doi.org/10.1016/S0140-6736(09)62163-2

[14] Tharavichitkul, E., Prasitwattanseree, S., Thipmate, C., Chakrabandhu, S., Klunklin, P., Onchan, W., et al. (2015) Treatment Results of Adjuvant Brachytherapy as Monotherapy in Endometrial Cancer: A Retrospective Study from Faculty of Medicine, Chiang Mai University. Journal of Cancer Therapy, 6, 34-39. http://dx.doi.org/10.4236/jct.2015.61005 
Scientific Research Publishing (SCIRP) is one of the largest Open Access journal publishers. It is currently publishing more than 200 open access, online, peer-reviewed journals covering a wide range of academic disciplines. SCIRP serves the worldwide academic communities and contributes to the progress and application of science with its publication.

Other selected journals from SCIRP are listed as below. Submit your manuscript to us via either submit@scirp.org or Online Submission Portal.
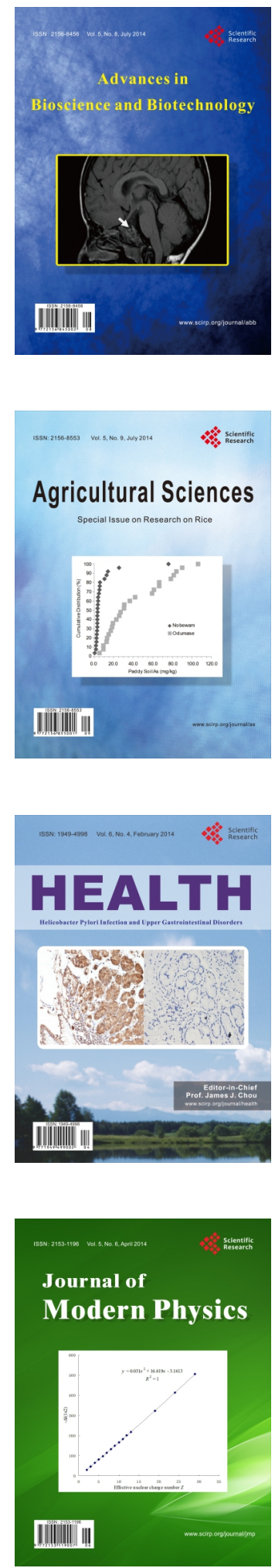
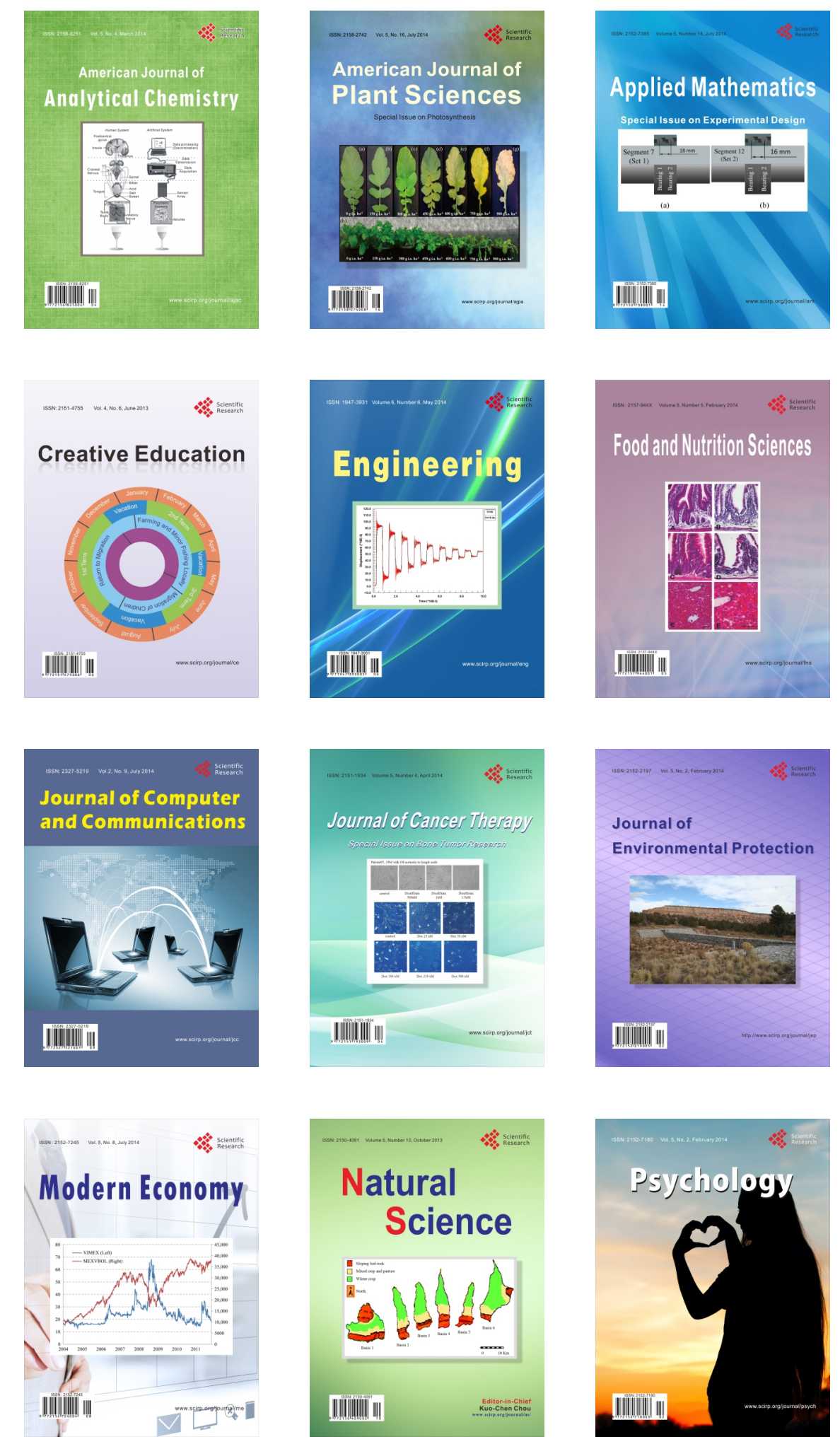